\title{
CSSR2019
}

6th International Conference on Science \& Social Research 2019

https://cssr.uitm.edu.my/2019/

Parkroyal Penang Resort, Batu Ferringhi, Pulau Pinang, Malaysia, 04-05 Dec 2019

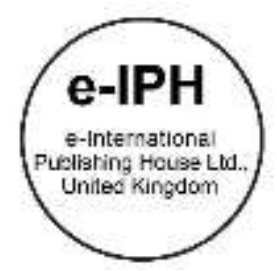

\section{Design Pedagogy: Pictographic design artefacts perceived artificial intelligence elements for product designers}

\author{
Mohd Hasni Chumiran, Shahriman Zainal Abidin \\ Department of Industrial Design, Faculty of Art and Design, Universiti Teknologi MARA, 40450 Shah Alam, Malaysia \\ hasniide@yahoo.com, shahriman.z.a@uitm.edu.my \\ Tel of 1st Author: +6013-2855448
}

\begin{abstract}
This paper interprets a design pedagogy based on the Internet of Things (loT) communication in the cyber-physical system challenges. This literature study discovers pictographic through artificial intelligence (Al). The product designers perceive the product form imaging beyond the engagement of design artefacts in the industrial design. The digital information sets are supplied through a design artefact evolution using heuristic evaluation. By the dual-method of designers' human cognition, the design concept continuum develops arts and design education. The results identify an exact meaning of design pedagogy that the academicians will understand the specific content analysis type.
\end{abstract}

Keywords: Artificial intelligence; industrial design; form imagery; internet of things

eISSN: 2398-4287@ 2021. The Authors. Published for AMER ABRA cE-Bs by e-International Publishing House, Ltd., UK. This is an open access article under the CC BYNC-ND license (http://creativecommons.org/licenses/by-nc-nd/4.0/). Peer-review under responsibility of AMER (Association of Malaysian Environment-Behaviour Researchers), ABRA (Association of Behavioural Researchers on Asians/Africans/Arabians) and cE-Bs (Centre for Environment-Behaviour Studies), Faculty of Architecture, Planning \& Surveying, Universiti Teknologi MARA, Malaysia.

DOI: https://doi.org/10.21834/ebpj.v6iSI4.2901

\subsection{Introduction}

The affirmation of design features within the growth of efficient product design arises from creating new product designs. The principle of new product development (NPD) is vital in categorising successful product features that could be delivered and validating the appropriate design methodology (Alli, 2015). Following the engineering design (ED) approach, NPD will enhance the value of the product criterion, especially in the field of industrial design (ID), which is fundamental to the design concept of emotion, aesthetics, and semantics (Abidin, 2012; Chumiran, 2016; Zainal Abidin, Sigurjónsson, Liem, \& Keitsch, 2008). Two standard design practices deal with some complimentary designs between ED and ID for the same NPD roadmap programme. The design methodology triangulation develops to perform the NPD with many problem-solving approaches transmitting the design concept accordingly (Abidin, 2012; Alli, 2015; Krippendorff, 1989). However, the meaning of transmission is a crucial challenge for product designers as the Industry 4.0 revolution has digitised the method of virtual design manufacturing (Brandmeiera et al., 2016; Chumiran, Abidin, Anwar, Vermol, \& Sirat, 2020).

This paper attempts to demonstrate a design pedagogy ${ }^{11}$ concept of virtual design and form imagery (pictographic design) utilising the design cognition of triangulation between design thinking and system thinking (Krippendorff, 1989; Oxman, 2008). This design pedagogy contextually describes that the product designer guides the Al elements for certain design traits based on the outsourced loT networks, which means the loT environment dependency sources and channel information navigate the NPD program concurrently.

\footnotetext{
$1_{1}$ Design pedagogy involves engagement in the "creative synthesis of ideas" to gain professional practice entry. It draws on a mix of elements that enable students to become independent, self-analytical, and critical thinkers and acquire tacit knowledge of their specialised work area (Oppenheimer, 2016).
}

eISSN: 2398-42870 2021. The Authors. Published for AMER ABRA CE-Bs by e-International Publishing House, Ltd., UK. This is an open access article under the CC BYNC-ND license (http://creativecommons.org/licenses/by-nc-nd/4.0/). Peer-review under responsibility of AMER (Association of Malaysian Environment-Behaviour Researchers), ABRA (Association of Behavioural Researchers on Asians/Africans/Arabians) and CE-Bs (Centre for Environment-Behaviour Studies), Faculty of Architecture, Planning \& Surveying, Universiti Teknologi MARA, Malaysia.

DOI: https://doi.org/10.21834/ebpj.v6iSI4.2901 
The structure of this paper structures on the chronology analysis that the basic knowledge of the Al concept could be displayed by digitising pictographic designs and synchronising the three components of design studies, namely people, processes, and products (Abidin, 2012; Anwar, Abidin, \& Hassan, 2015; Chumiran, Abidin, Anwar, Vermol, \& Sirat, 2020).

\subsection{Literature Review}

This paper expresses the chronological order ${ }^{2}$ of a design study concept to screen the basic Al knowledge by digitising the pictographic design. Product designers are selected as design experience participants because they usually work within manufacturing organisations in tiny design workgroups known as the research and development (R\&D) department (Alli, 2015). The designers begin from the data sources from loT networks with the visual of product imagery to address the semiotic sign (Abidin, 2012). Then, they use both principle and theory to elaborate the product imagery datasets into certain design features through the design patterns. These activities describe how design studies are specifically associated with a focus group in the R\&D department (Cross, 1999, cited in Anwar, Abidin \& Hassan, 2015).

Exploring the formed imagery is based on the (1) line and (2) visual perspective, which implies methods from freehand sketching to digital drawing (Paricio, 2014) to compute a three-quarter front view of digital photographic imaging (Abidin, 2012; Taylor, 2006). Throughout the experience of design practices, the stimuli of three main components, which are design history, industry method, and practice properly shape the visual communication understanding (Frayling, 1993, cited in Anwar, Abidin, \& Hassan, 2015). It bears the product designer's mind that the varnishing point (two-point perspective setting) similarly develops the product image. The patterned point of view (POV) virtually accommodates the product design creation's standard set-up view. Here, the designer's behavioural practice usually shapes and implicitly allows design thinking and system thinking (Mohamed Kamil, Abidin, \& Hasdinor Hassan, 2018; Abidin, Bjelland, \& Øritsland, 2008).

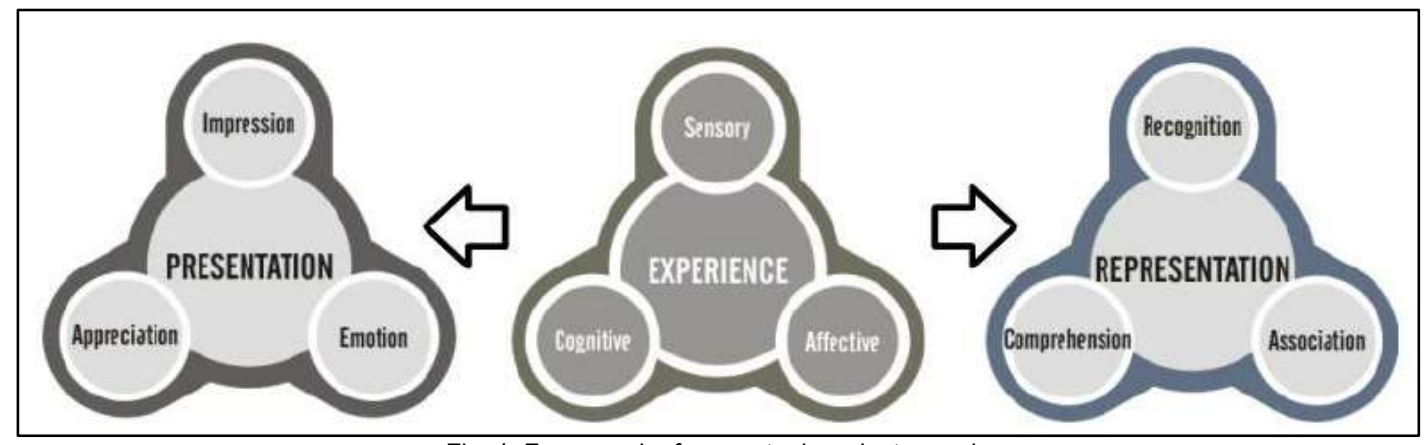

Fig. 1: Framework of perceptual product experience (Warrel, 2008, cited in Abidin, 2012)

Abidin (2012) prefers the researcher to use the perceptual product experience framework (PPE Framework), which was introduced by Warrel (2008) as a model of experience (refer to Figure 1). The PPE framework's role is to recognise the value of the product form that logically perceives in the natural way, which encompasses the visual and quality appearances of the design (Abidin, 2012). It is humancentred on the experience of product design (core mode) in which the product designer simultaneously applies their sensory, cognitive, and affective modes. Meanwhile, the two dimensions (presentation and representation) describe design phenomena (Abidin, 2012).

In this case study, the product imagery fell into the representation dimension. Three sub-modes (recognition of type, comprehension of characteristics, and association to values) anchor the Al elements for specific design features based on the outsourced loT networks. This sequence of design activities demonstrates a common approach in NPD's design practice in industry method classification (Abidin, Warell, \& Liem, 2011, Abidin, 2012; Anwar, Abidin \& Hassan (2015); Alli, 2015; Zainal Abidin, Anwar, \& Rahim, 2020). Hence, to address the semiotic sign, this study defines the design discipline narrative according to the chronological order and the visual of product imagery.

\subsection{Design Pedagogy in the Industrial Design Field}

Nowadays, the R\&D working environment consists of several product developers' internal networks to search and identify design information from real-world gateways to form out of the box, real-life, and distinctive designs that began on design practices (Tovey, 2015). However, because of the reflective design practice, understanding design studies' information will allow the designing medium for the arts and design education by academic institutions, design pedagogy, to shape a shuttle and commute concept (Oxman, 2008). Like teachers in the classroom who use the conception of pedagogy, product design managers teach and train their team members in the design discipline for the business environment activities. The R\&D design studio usually interacts using the loT communication to convey "a deep understanding of the designerly way of knowing" to the professional designers (Tovey, 2015). Internal design activities such as studio training, design workshop, modelling course, brainstorming session, and critical thinking are created the design

\footnotetext{
${ }^{2}$ Merriam-Webster (2019) defines chronological order as "of, relating to, or arranged in or according to the order of time". This describes the moment of design activities (time of design discipline) to achieve quality job function and/or task by the industrial design field's objective. This description coincides with the experts' practice sequences, Bandara, Gorbacheva, \& Beekhuyzen (2015).
} 
experience into reflective practice (Chumiran, Abidin, \& Mohamed Kamil, 2020; Mohamed Kamil, \& Abidin, 2015). This tacit knowledge brings some approaches to frame problem identification and design solution.

Realistically, changes in design media are nothing new, particularly in the Industry 4.0 era (Ratnasingam et al., 2020; RomeroGázquez et al., 2020; Oxman, 2008). However, this study found that the ID field's frequent challenges come from the changes in processes rather than changes in the architectural knowledge base. An example of the situation shown in Figure 2 where designers use digital media such as a digital pen tablet or a sketching tablet (Autodesk SketchBook) and computer-aided design (Alias CAD-3D modelling). It replicates an artefact to purposefully comprehend the design experience (Abidin, 2012; Paricio, 2014; Taylor, 2006).

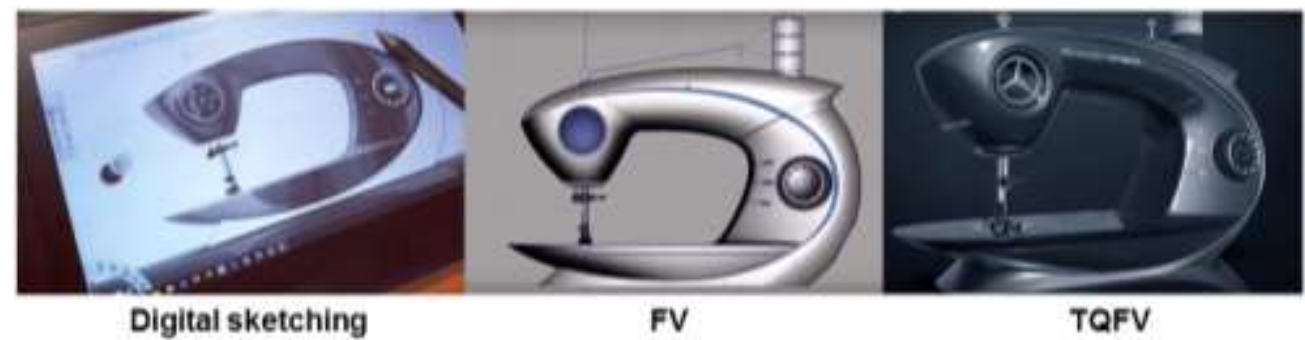

Fig. 2: Digital design process ${ }^{3}$ - Front view (FV) and three-quarter front view (TQFV) (Collin Smith (2019) Autodesk SketchBook Blog)

In advanced virtual reality (VR), the quality of the design concept recognised in a digital 3D experience and "the use of virtual reality techniques improved the experience in the validation of aesthetical, proportions, functional and ergonomics aspects applied in an academic scenario" (Estrada \& Gomez, 2013). Industry players' knowledge of design practice has improved tremendously to prompt changes in the arts and design education and design pedagogy.

\subsection{Heuristic Method}

The heuristic method recognises two steps for analysing the Al element datasets: (1) the triangulation of design cognition into (2) the conception of a design bridge. Having validated by the heuristics method, this study used the morphing study (Akner-Koler, 2000), which derives the semantics design thinking that the bipolar photographic images (adjective and antithesis; beauty and ugly) will intuitively align the design continuum scale (Abidin, 2012; Chumiran et al., 2018; Chumiran, Abidin, \& Mohamed Kamil, 2020; Zainal Abidin, Anwar, \& Rahim, 2020). Using the semantics of pictographic design artefact will result in the emergence of the semiotic signs. Also, it can visualise and organise the chronological order representing imagery in the product form (Abidin et al., 2016).

\subsection{Triangulation of design cognition}

Abidin (2012) triangulated two design knowledge perspectives using (1) the visual elements study by Akner-Koler (2000) and (2) the principle solution study by Wim Muller (2012). The finding showed integrating product forms from both a qualitative and quantitative simultaneously structure to comprehensively address the aesthetic value and product.

As shown in Figure 3, focusing on the ID context, evidence of form integration is developing the visual elements (VE) in design cognition with zoomorphism (animal to a car). This VE comprises four basic properties- point, line, plane, and volume-that evoke the intuitive tone and texture of the design composition. It thus develops images and forms representing the two perspectives as 2dimensional (2D) and 3-dimensional (3D) concepts.

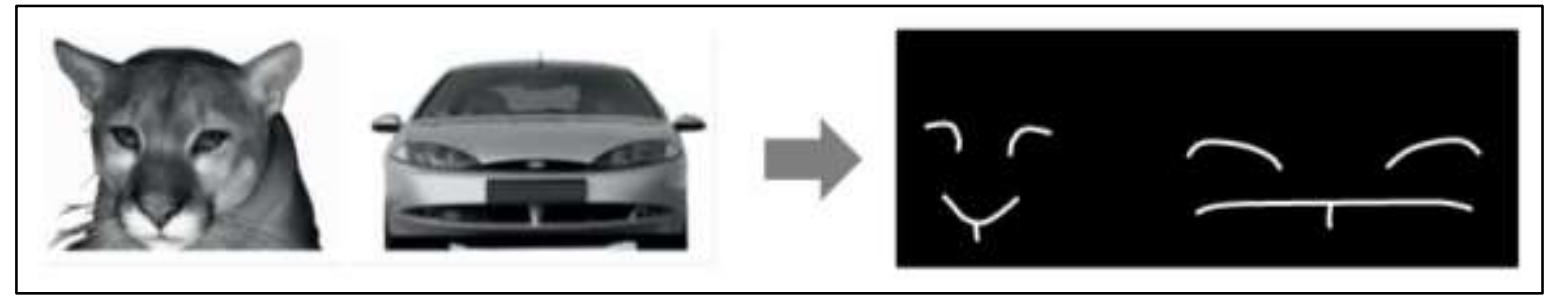

Fig.3: Cougar (animal) and Ford Cougar (car) with a simple VE screening (Abidin, 2012)

Furthermore, it reflects the design methodology through an appropriate protocol to understand designers' design thinking (Abidin, Christoforidou, \& Liem, 2009; Chumiran, Abidin, \& Mohamed Kamil, 2020).

\footnotetext{
${ }^{3}$ Source: Collin Smith (2019) Autodesk SketchBook Blog: https://blogs.autodesk.com/sketchbookpro/industrial-design-from-sketch-to-concept-model/
} 


\subsection{The conception of a design cognition}

Consequently, the ID field knowledge presents the metaphor visualisation. On the other side, bipolar digitisation representing the algorithm digitisation in the ED field. According to the semantic design scale, the combination emerges called a fusion design (see Figure 4). The method has accommodated a design bridge between both fields (Abidin, 2012). The notion of design similarity makes it possible to generate the disclosure approach (dual methodology) in reaching a design roadmap by triangulating two distinct domains (Krippendorff, 1989). Therefore, the design scaling structure acknowledges a fusion of design development, which is complemented and recognised by the descriptive and prescriptive strategies. In other words, the fusion design (the bridge) does not have any knowledge gap.

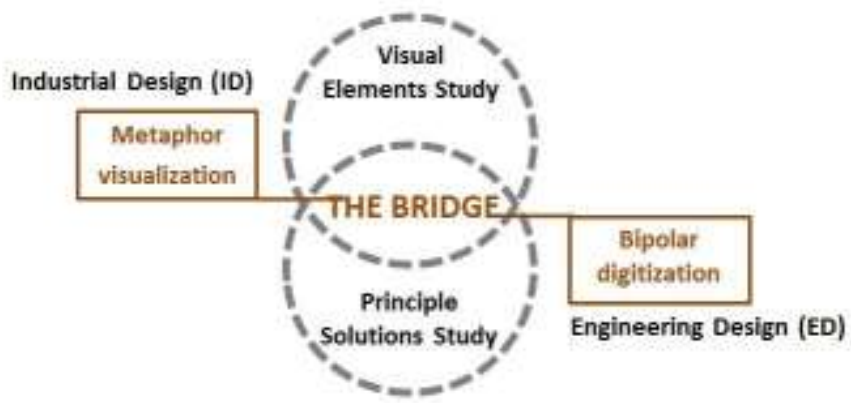

Fig.4: Bridge heuristic method - design experience triangulation (Abidin, 2012)

However, product orientation has the same function (category) in semantics design thinking. For the fundamentals of a fusion design example, a study has defined and verified the conception of a hybrid electric vehicle. ${ }^{4}(\mathrm{HEV})$ in terms of the similarity and coincide with the green energy concept on a zero-emission programme. A mixture of two different natural sources with (1) fuel energy supplies the mechanical part (internal combustion engine). While (2) electrical energy, which is produced by the electric generator (electric motor) and delivered to the car drivetrain (the component that delivers power to the driving wheels). It aims to produce an alternating process for the form design for both types of energy in the green energy transportation concept (Denton, 2004).

\subsection{Results and Discussion}

\subsection{Al elements for the transformation of the design pedagogy}

The visual elements (VE) can screen the photographic design artefact, which combines two primary entity lines: geometric and organic (Abidin, 2012). Consequently, the semiotics sign extraction allows a horizontal continuum is created, which implies the transition of object characteristics between the plane- $X$ axis (semantics order) and the plane- $Y$ axis (levelling order). In this part, the design experience requires the product designers to heuristically morph the form pattern's evolution following the taxonomy of Table 1.

Table 1. The taxonomy of a heuristic table

\begin{tabular}{lll}
\hline Quality review of a design morphing & Plane-X (Semantics) & Plane-Y (Leveling) \\
\hline Geometric form & 1 & 1 \\
Transitional form & 2 & 1 \\
Merging form & 3 & 2 \\
Transitional form & 4 & 3 \\
Organic form & 5 & 3 \\
\hline
\end{tabular}

Therefore, a morphing strategy study is required to construct a dual-axis plane- $X$ and $Y$. Therefore, the design pedagogy can apply the design goal setting to reach and select the theme of Al elements (fusion design as a bridge) following the case study (design practice based) in the earlier heuristic method.

\subsection{The sustainable development goal of fusion design through design education}

Referring to Chumiran (2016), Dyson.com (2014) initially published the fusion design using semantic design thinking, as illustrated in Figure 5 . The fusion product form concept is revealed as an ecodesign identity similar to the environmentally friendly product design. This critical value in exchange is related to user interaction as the centre of user experiences (Jantan, Kamaruddin, Abidin, Said, \& Ramli, 2020).

\footnotetext{
4 "HEV is an internal combustion (IC) engine that produces dangerous emissions and has poor efficiency at the part load. Electric drives produce ' $\mathrm{no}$ ' emissions but have a limited range." (Denton, 2004).
} 
Due to the structure of semantic thinking, this ecologically mapped is to recognise an energy-saving theme for a setting. Thus, under the new Industry 4.0, green technology is developed to interact with loT communication as a profound knowledge for designers to produce skilled developers as part of the sustainable development goal (SDG). The fusion design (energy saving) articulates the universal characteristics in semantics design thinking, affecting design education. The theme has provided insights into the semiotic sign of product form quality: an academy that understands the importance of design role, function, and digitisation.

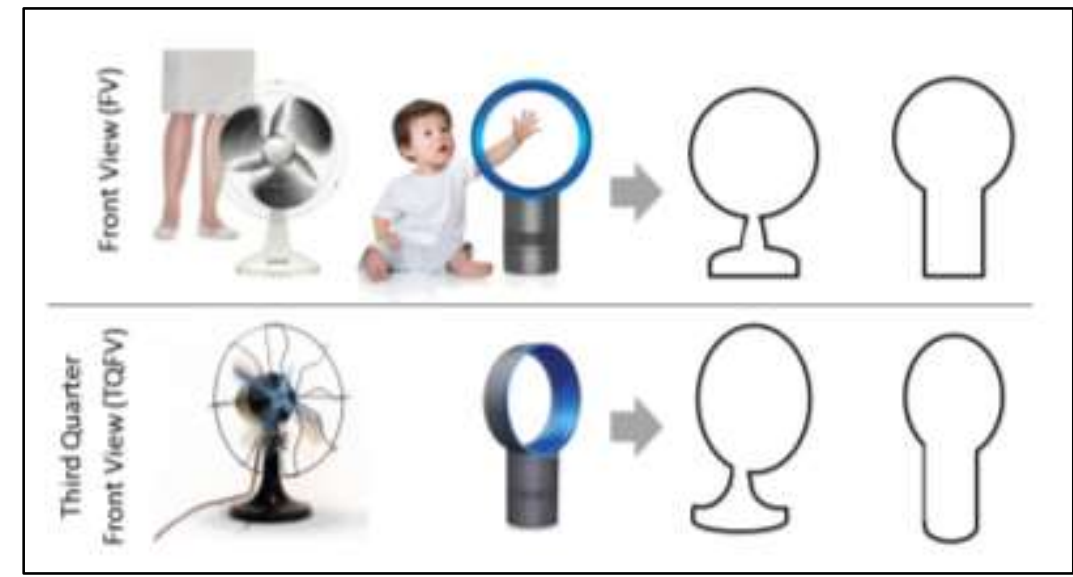

Fig.5: Photographic design artefact with VE imaging - design experience

\subsection{Conclusion}

Industry players and academics in design education can network in two-way flows on design pedagogy communication, starting with pictographic imagery of the product form, interpretation of the design supply chain, then moving to the product-service system and design information. Semantic design thinking has been discovered in understanding the Al elements of the NPD roadmap based on loT orientation. It has completely covered the design studies knowledge and the fusion conceptualism meaning in R\&D pre-post activities. Having some representative dataset, a logical mechanism doctrine in design cognition has digitised whereby all levels of the designer's skills used to approach the semiotics sign product form. All these were explored and generated using the design event continuum, specifically under the chronological content analysis. However, the discovery of the metaphor pattern requires a morphing strategy in further design studies. Based on the form-giving design research entity orientation, the study will connect some knowledge gaps in the digitisation of product form.

\section{Acknowledgements}

This research is supported by the Institute of Research Management \& Innovation (IRMI), Universiti Teknologi MARA (UiTM), Malaysia - No.: 600-IRMI/MyRA 5/3/REI (002/2018). This support is gratefully acknowledged.

\section{References}

Abidin, S. Z. (2012). Practice-based Design Thinking For Form Development and Detailing, Trondheim, (Norwegian University of Science and Technology)

Abidin, S. Z., Bjelland, H. V., \& Øritsland, T. A. (2008). The embodied mind in relation to thinking about form development. In Proceedings of NordDesign 2008 Conference (pp. 265-274).

Abidin, S. Z., Othman, A., Shamsuddin, Z., Samsudin, Z., Hassan, H., \& Mohamed, W. A. W. (2016). Identifying sequence maps or locus to represent the genetic structure or genome standard of styling DNA in automotive design. Advances on Mechanics, Design Engineering and Manufacturing, 1159-1166. doi:10.1007/978-3-319-457819_116

Abidin, S. Z., Christoforidou, D., \& Liem, A. (2009). Thinking and re-thinking verbal protocol analysis in design research. In DS 58-2: Proceedings of ICED 09, the 17th International Conference on Engineering Design (Vol. 2, pp. 1-12).

Abidin, S.Z., Warell, A., \& Liem, A. (2011). The significance of form elements: A study of the representational content of design sketches. In Proceedings of the DESIRE'11 Conference on Creativity and Innovation in Design (pp. 21-30). DOI: 10.1145/2079216.2079219

Akner-Koler, C. (2007). Form and Formlessness, Sweden, (the Chalmers University of Technology and University College of Arts)

Alli, H. (2015). A Design Methodology Incorporating User Requirements and Preferences For a Successful Product, Kuala Lumpur, (University Malaya).

Anwar, R., Abidin, S. Z., \& Hassan, O. H., (2015). A Practical Guideline To Quantifying Qualitative Analyses Of Design Cognition, The Turkish Online Journal of Educational Technology (IETC 2015), Special Issue 1, $13-21$. 
Bandara, W., Gorbacheva, E., \& Beekhuyzen, J. (2015). Achieving Rigor in Literature Reviews: Insights from Qualitative Data Analysis and Tool-Support. Communications of the Association for Information Systems, 37.

Brandmeiera, M., Bognera, E., Brossoga, M. \& Frankea, J. (2016). Product design improvement through knowledge feedback of cyber-physical systems, 26th CIRP Design Conference, Procedia CIRP 50, 186 - 191.

Chumiran, M. H. (2016). The Impact of 3R's Element Creation on Ecological Form of Ecodesign in Malaysia. (MA Thesis, Universiti Teknologi MARA).

Chumiran, M. H., Abidin, S. Z., Anwar, R., \& Alli, H. (2018). Extrapolative Morphs Design Thinking As An Intangible Ecological Form To Emerge Ecodesign Identity, CSSR2018

Chumiran, M.H., Abidin, S. Z., \& Mohamed Kamil, M. J. (2020). Pre-Post Observation Research Fosters a Preliminary Study in Product Form Identity. In L., Buck, E. Bohemia, \& H. Grierson, Proceedings of the 22nd International Conference on Engineering and Product Design Education, E and PDE 2020 Institution of Engineering Designers, The Design Society.

Chumiran, M.H., Abidin, S.Z., Anwar, R., Vermol, V.V., \& Sirat, A. (2020). 3R Evokes Ecodesign Identity in Ecological System of Green Manufacturing. International Journal of Supply Chain Management. 9(3), pp. 182-190.

Denton, T. (2004). Automobile Electrical and Electronic System, Third Edition, GB: Elsevier Butterworth-Heinemann.

Estrada, J. C. A., \& Gómez, G. O., (2013). Augmented Reality Application for Product Concepts Evaluation, International Conference on Virtual and Augmented Reality in Education, Procedia Computer Science 25, Elsevier, 389 - 398

Jantan, R., Kamaruddin, N., Abidin, S.Z., Said, T.S., \& Ramli, H. (2020). Value in exchange: The importance of user interaction as the centre of user experiences. International Journal of Innovation, Creativity and Change, 11(10), pp. 75-83.

Krippendorff, K. (1989). Product Semantics '89, Product Semantics: A Triangulation and Four Design Theories, 1-32.

Mohamed Kamil, M. J., \& Abidin, S.Z. (2015). Unconscious interaction between human cognition and behavior in everyday product: A study of product form entities through free hand sketching using the design syntactic analysis. Proceedings of the 17th International Conference on Engineering and Product Design Education (E\&PDE15), Great Expectations: Design Teaching, Research \& Enterprise, Loughborough, UK, 03-04.09.2015 (p.369-374)

Mohamed Kamil, M. J., Abidin, S.Z., \& Hasdinor Hassan, O. H. (2018). The investigation of designers' Reflective Practice Activity Using Verbal Protocol Analysis, Proceedings of the 20th International Conference on Engineering and Product Design Education (E\&PDE 2018), Dyson School of Engineering, Imperial College, London. 6th - 7th September 2018, (p. 363-368)

Oxman, R. (2008). Digital architecture as a challenge for design pedagogy: theory, knowledge, models and medium, Design Studies, Volume 29, No. 2, 99-120.

Paricio, J., (2014). Perspective Sketching - Freehand and Digital Drawing Techniques for Artists and Designers, Singapore: Page One Publishing.

Ratnasingam, J., Yi, L.Y., Abdul Azim, A., Halis, R., Choon Liat, L., Khoo, A., Mat Daud, M., Senin, A.L., Ab Latib, H., Bueno, M.V., Zbiec, M., Garrido, J., Ortega, J., Gómez, M.V., Hashim, R., Zakaria, S., Zainal Abidin, S., \& Mat Amin, M.N.Z. (2020). Assessing the awareness and readiness of the Malaysian furniture industry for Industry 4.0. BioRes. 15(3), 4866-4885.

Romero-Gázquez, J.L., Cañavate-Cruzado, G., Ortega-Gras, J.J. Garrido-Lova, J., Bueno-Delgado, M.V., Gómez-Gómez, M.V., Zbiec, M., Ratnasingam, J., Abidin, S.Z., Hashim, R., Zakaria, S., \& Zamri Mat Amin, M.N. (2020). Making 4.0: Developing an Official Master Degree for Adapting the Curricula of Future Workers and Managers of Wood and Furniture Sector to the Skills Required by the Industry 4.0. In Proceedings of 12th International Conference on Education and New Learning Technologies (EDULEARN 2020), pp. 7968-7977.

Taylor, T., (2006). How to Draw Cars Like a Pro, 2nd Edition, Motorbooks Studio, USA

Tovey, M., (2015). Development in Design Pedagogy, E\&PDE15, Loughborough: UK. 188-193.

Zainal Abidin, S., Anwar, R., \& Rahim, W.N. (2020). The Presence of Fibonacci Sequence in Malaysia Keris Design Related to Elements of Art and Principles of Design. Environment-Behaviour Proceedings Journal, 5(SI3), 141-147.

Zainal Abidin, S., Sigurjónsson, J., Liem, A., \& Keitsch, M. (2008). On the role of formgiving in design. In DS 46: Proceedings of E and PDE 2008, the 10th International Conference on Engineering and Product Design Education. 